the car platform level, the driver can exercise control so as to cause the platform to incline to either one side or the other. With the car at rest on the curve, some packing blocks were laid on the ground reaching to within about a foot of the chock on one side of the car. 'The driver then inclined the car so that the chock rested on the packing blocks; some planks were laid resting on the ground at one end and against the car platform at the other, so as to extend the inclined plane of the platform down to ground-level. The packing cases were then easily shoved off without the assistance of any tackle whatever. On unloading being completed, the driver caused the car to recover level immediatcly. Mr. Brennan has not yet published a complete description of the mechanism for bringing the gyrcscopes back to their central position, certain patents having been applied for and not yet granted.

We then had an opportunity of taking a run round the circle. All passengers stood, and, despite the fact that there was nothing to take hold of, perfect steadiness of
THE FUEL QUESTION IN THE UNITED STATES.

A $N$ important department of the United States Geological Survey is that devoted to fuel. More than $400,000,000$ tons of coal, valued at above 106,000,000l., were raised in 1908 , nearly the whole of which was consumed in the country, and this department has made numerous researches as to the best methods of utilising this coal. The information acquired is published from time to time in the form of bulletins, most of which are supplied free or at a nominal cost. Four bulletins recently issued, Nos. $373,382,383$, and 385 , may be taken as indicating the scope of the work done. They are entitled "The Smokeless Combustion of Coal in Boiler Plants," by D. T. Randall and H. W. Weeks; "The Effect of Oxygen in Coal," by D. White; "Notes on Explosive Mine Gases and Dusts," by R. T. Chamberlin; and "Briquetting Tests at the United States Fuel-testing Plant, Norfolk, Virginia, 1907-8," by C. L. Wright. The paper on

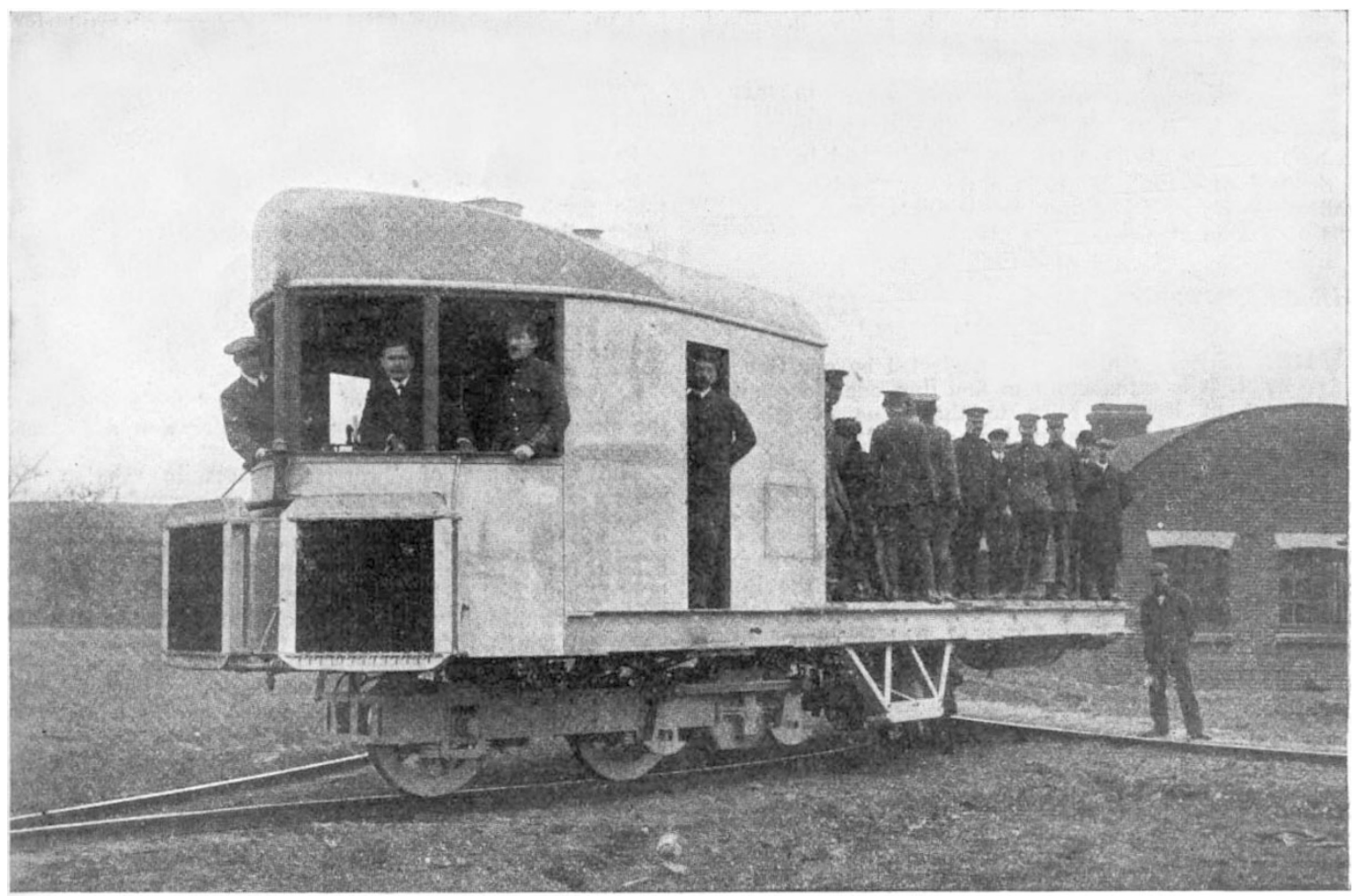

The Brennan Mono-Rail Vehicle.

equilibrium was experienced by everyone. The angle of heel inwards we estimated to be about ro degrees on this trip. An exhibition of the vehicle taking sharp curves followed, the minimum radius being 35 feet, after which we had a trip at high speed down the straight portion of the track and back again. Complete success attended all the trials, and Mr. Brennan is to be heartily congratulated on the results.

From our previous description of the track it will be understood that its simplicity renders it very suitable for military purposes. The short cross-sleepers are simply laid on the ground without ballast, and we noted on this visit that, at one part of the straight line, longitudinal sleepers had been used. At the factory entrance a short part of the line is flush with the surface of the macadam, illustrating the value of the system for tramway work. It is intended to put in hand one or more trailers to be coupled to the present vehicle, in order to show the practicability of running such vehicles on trains. briquetting is chiefly of interest to the mine-owners and coal-users of Virginia, although the summary of the recent literature on briquetting possesses a wider value. The work described by R. 'T. Chamberlin in the memoir on explosive mine gases and dusts had only just commenced when, in December, 1907, a series of unusually disastrous explosions took place in the Naomi, Monogah, and Darr mines of Pennsylvania and West Virginia. This led to a diversion of the original inquiry, the gas and dust concerned in these explosions being subjected to a detailed examination. Special attention was given to the part played by the methane evolved from the coal in the production of these explosions, this gas being more rapidly evolved the finer the state of division of the coal. After this emission of methane had gone on for some time the dust was less readily ignited, and experimental evidence is given showing that the fresh dust is more dangerous than old dust.

The memoir by Mr. D. White, on the effect of oxygen No. 2105 , VOL. 83] 
in coal, proves, from the calorimetric point of view, that high oxygen is practically equivalent to high ash. It is also shown that the ratio of hydrogen to oxygen is the best measure of the coking efficiency of the coal, and the effect of the oxygen on the weathering of the coal is also discussed.

The bulletin by Messrs. D. T. Randall and H. W. Weeks, on the smokeless combustion of coal in boiler plants, is of especial interest in the United States, where the regulations against the production of smoke are severe, and strictly enforced. Between 400 and 500 steam plants in thirteen of the larger cities vere visited, the data from 285 plants being made use of in this report. The general conclusion is that the smokeless combustion of bituminous coal is possible, and there are many types of furnaces and stokers that are operated smokelessly. The guiding principle is that stokers or furnaces must be set so that combustion is complete before the gases strike the heating surface of the boiler. The plant must be designed for the type of coal it has to burn; no one type of stoker is equally valuable for burning all kinds of fuel. It is worthy of note that, among the numerous stokers described, no mention is made of boilers using powdered fuel, a type particularly well adapted for the smokeless combustion of bituminous coal. The amount of experimental work given is very large, no fewer than fifty-seven tables of results accompanying the text. It is a work which should be in the hands of every engineer responsible for a steam plant. At the end of the bulletin is a bibliography of the survey publications on coal and fuel testing, and also of publications on smoke abatement.

\section{THE SCIENTIFIC REPORTS OF THE LOCAL GOVERNMENT BOARD.'} W HEN science as a whole is neglected by our Govern-
ment, it is satisfactory to find that one Government Department at least is alive to the value of scientific research, and is able by annual grants to investigators to assist research and to produce the admirable work contained in the reports under review. It may be hoped, apart from other considerations, that the example of the Local Government Board may serve a useful purpose in encouraging similar work by other Government Departments. These reports of the Medical Officer of the Board are now being issued much earlier than previously, a fact of moment, for the practical value of a research is often diminished by delay in publication.

Dr. Andrewes furnishes a second report on the bacteria of sewer air. He finds the bile-salt neutral red lactose agar medium of McConkey well fitted for the detection of bacteria belonging to the $B$. coli group. In the drain air of a large public institution and of a private dwelling sewage bacteria can be readily demonstrated, but their presence is of a highly intermittent character. The deter. mining cause of the access of sewage bacteria to drain air appears to be droplet contamination from splashing. Dr. Andrewes and Dr. Horder have continued observations on the defences of the body against the pyogenic cocci, commenced last year by Drs. Andrewes and Gordon, and their joint report contains matter of much interest.

In view of outbreaks of cerebro-spinal fever, Drs. Gordon and Horder investigated the relative efficacy of the various anti-meningococcus sera on the market; the sera tested on animals possessed practically no curative or prophylactic value. Treatment with a vaccine, however, gave some promising results. It is to be noted that Flexner and Jobling have obtained very encouraging results in the treatment of epidemic cerebro-spinal fever in man with anti-meningococcus serum.

Dr. Savage submits reports dealing with mastitis in cows ("garget"). Some 70-75 per cent. of the cases are associated with a streptococcus having special characteristics, and termed the $S$. mastitidis; but it is significant, and throws doubt on the specificity of the organism. that the same streptococcus was found in milk from unaffected quarters of the udder. The explanation may be that, as in other microbial diseases, the organism becomes pathogenic

1 Thirty-seventh and Thirty-eighth Annual Reports of the Local Government Board, $1907-8$ and ro08 -9 . Supplements containing the Reports of the
Medical Officer for $1907-8$ and 1908-9.

NO. 2 IO5, VOL. 83] only under special conditions. "The streptococci present in cases of human sore throat were also investigated, and were found to be of the $S$. anginosus type.

These two streptococci, morphologically and culturally, are indistinguishable, but show marked differences in their pathogenicity on animals. Thus the mastitis variety is non-virulent to mice and other rodents, but is capable of inducing a mastitis in goats; the anginosus variety, on the other hand, is virulent to mice, but fails to induce mastitis in goats. Dr. Savage therefore suggests that it may be possible to determine whether streptococcal outbreaks of human throat disease are due to milk by the capacity of the streptococci of the human disease to cause mastitis in goats by infection of the teats.

Dr. Savage has also continued his investigations on the cultural reactions and on the presence of bacilli of the Gartner group in the intestinal tract of animals, and in a second report discusses the presence of paratyphoid bacilli in man. It is pointed out that the hog-cholera bacilli are indistinguishable from paratyphoid types, and the suggestion of a connection between paratyphoid fever in man and the bacilli so frequently found in cases of swine fever is an interesting hypothesis, but the balance of evidence at present available seems to be distinctly opposed to anv xtiological relationship. Most cases of paratyphoid fever in man are probably associated with specifically contaminated food, but the precise paths of infection cannot yet be said to have been determined.

Reports are contributed by Dr. Sidney Martin on the toxic products of streptococci. The first deals with the pathogenicity and toxins of the streptococcus (S. faecalis), so common in the intestinal contents. Injected intravenously into rabbits, this organism produces vegetative endocarditis of the mitral valve of the heart; this may have some bearing on the ætiology of acute rheumatism. The endotoxin on inoculation produces fall of temperature and great bodily weakness.

In the second the mode of growth and toxic products of the streptococcus ( $S$. pyogenes) of suppuration are investigated.

The occurrence of "carrier" cases in relation with enteric fever is the subject of a memorandum by Dr. Theodore Thomson and Dr. Ledingham. The problem of "carrier" cases, i.e. individuals in whom the typhoid bacilli persist for long periods after an attack of enteric fever, is a difficult and serious one. Treatment with vaccines and with sour milk have failed to eliminate the bacilli from cases on which they have been tried.

A very important report on the prevalence and sources of tubercle bacilli in cows' milk is contributed by Prof. Delépine. The conclusions are based on an examination of 5320 samples, and 474 . or 8.9 per cent., proved to be tuberculous. Various administrative measures are discussed for the eradication of bovine tuberculosis. Details of experiments on the effect of the storage of glvcerinated vaccine lymph at temperatures below the freezing point are contributed by Dr. Blaxall and Mr. Fremlin. Cold storage at $-5^{\circ} \mathrm{C}$. for six months in no way diminished the activity of the lymph, and for two years only brought about a reduction in activity of about 2 per cent.

This necessarily brief survey of the contents of these volumes may, it is to be hoped, direct attention to the important researches carried out for the Local Government Board, and prevent the papers from being overlooked by those who are carrying out work in the same fields.

R. T. HEWLETT.

\section{SCIENTIFIC ACTIVITY IN NEW ZEALAND.}

THE Philosophical Institute of Canterbury, New Zealand, is one of several very active scientific societies in Australasia. The annual report for the year 1909, presented to the annual meeting held last December, is a record of the continued success of the institute in its scientific undertakings. During the year the publication of the results of the expedition to the sub-Antarctic islands of New Zealand was steadily proceeded with under the editorship of Dr. C. Chilton. The reports upon the work will consist of two quarto volumes of about 400 pages each, and will be illustrated with numerous plates (some coloured), photographs, and text-figures; they will be 